\title{
La construcción de "la loca" en dos novelas chilenas: El lugar sin limites de José Donoso y Tengo miedo torero de Pedro Lemebel
}

\author{
Construal of "the Queen" in two Chilean novels: \\ El lugar sin limites by José Donoso and Tengo miedo torero by \\ Pedro Lemebel \\ BerTa López Morales
}

Universidad del Bío-Bío. Chillán, Chile

blopez@ubiobio.cl

\section{RESUMEN}

Este artículo intenta mostrar cómo se construye la identidad sexual y social del personaje "la loca” en dos novelas chilenas, El lugar sin limites de José Donoso y Tengo miedo torero de Pedro Lemebel. De este modo se establece un diálogo entre ambas novelas, centrado en los distintos efectos que tiene el vestido y el nombre como actos performativos tanto en el devenir de los(as) protagonistas como en las diferencias entre el deseo homoerótico sometido a los espacios y límites impuestos por la norma hegemónica, y ese mismo deseo que se niega a la exclusión y el rechazo. Para ello se han utilizado los aportes de la teoría queer: Kosofsky Sedgwick (1998), Eribon (2001, 2004), Bersani (1998), Foucault (1990, 2001), Butler (2005, 2006).

Palabras claves: Performativo, identidad homosexual, deseo homoerótico, poder hegemónico.

\section{ABSTRACT}

The aim of this article is to show how the sexual and social identity of the character "the Queen" is construed in two Chilean novels, El lugar sin limites by José Donoso 
and Tengo miedo torero by Pedro Lemebel. For this purpose, a dialogue is established between both novels focused on the different effects the dress and the name have as performative acts on the evolution of the protagonists as well as on the contrasts shown by homoerotic desire confined to the places and boundaries imposed by the hegemonic power, a desire that also opposes exclusion and rejection. The contributions on queer theory by Kosofsky Sedgwick (1998), Eribon (2001, 2004), Bersani (1998), Foucault (1990, 2001), Butler (2005, 2006) have been used to achieve this goal.

Keywords: Performative, homosexual identity, homoerotic desire, hegemonic power.

Recibido: 28-05-2010. Aceptado: 12-10-2010.

\section{INTRODUCCIÓN}

La homosexualidad es un tema recurrente en la literatura. Muchos relatos se han construido en torno al personaje homosexual en un afán por develar su "rareza", por entender su conducta o por explorar su interioridad. La mayoría de las novelas que abordaron el tema a comienzos del siglo XX lo hicieron desde el punto de vista de la norma sexual hegemónica: la heterosexualidad. Sólo en la segunda mitad del siglo XX, en el umbral del posmodernismo, surgen las voces disidentes y la reflexión teórica para mostrar la naturaleza de esta "singularidad", su identidad inestable y su inscripción problemática en una sociedad en que la homosexualidad es considerada antinatural, inconcebible e insoportable.

Guide, Proust, Genet, entre otros, inscribieron la figura del homosexual en sus obras literarias hurgando en los laberintos de aquella "rareza legítima" como la llamó René Char, escudriñando con avidez, premura y desconcierto en la angustia, la soledad y el rechazo que los estigmatizaba. La narrativa de estos y otros escritores homosexuales contribuyó a descorrer el tupido velo que la sociedad había tejido a su alrededor: material inestimable para los nuevos teóricos que han erosionado las bases de la norma sexual hegemónica. Estos escritores, sin embargo, no mostraron abiertamente su homosexualidad, fueron sus textos contradictorios, chocantes o descarados los que deslizaron la ambigüedad, y cierta molestia o desazón que anunciaban otra manera de sentir, de transgredir lo establecido, instalando el personaje del homosexual en la vasta galería literaria. 
Entre estos tipos literarios cabe destacar el personaje de "la loca" ${ }^{\text {, cons- }}$ tructo social aplicado a un individuo que sugiere por su anatomía un hombre, pero en el que su lenguaje y gestualidad señalan un comportamiento femenino, atrayendo sobre sí la atención, las burlas y el menosprecio, es el callejero, el habitante del prostíbulo. Diferente del invertido o pederasta como ha sido analizado en Amasijo por Marta Brunet (1962) en consonancia con el psicoanálisis. Los términos gay y queer ${ }^{2}$, acuñados en la actualidad, no han sido incorporados en nuestro país, con la carga reivindicativa que los escritores y teóricos homosexuales asignan a tales vocablos.

Resulta interesante, aunque no es el propósito de este artículo, trazar una línea divisoria entre los que escriben sobre la homosexualidad, es decir, escritores heterosexuales que construyen las heterotopías ${ }^{3}$ (Eribon, 2001: 469) del personaje homosexual, los espacios distintos, donde deviene, transita o se oculta, y aquellos que escriben desde su homosexualidad confesa, bajo el marbete de literatura gay, viviendo su diferencia no como un reto o un destino imposible.

De acuerdo con la división anterior, la novela El lugar sin límites (Donoso, 1981) es un relato sobre un personaje homosexual, que transita en una sociedad cuya norma es la heterosexualidad donde su transgresión adquiere

${ }^{1} \mathrm{Al}$ respecto, en una entrevista Pedro Lemebel afirma: "Existe una homosexualidad gay, blanca, apolínea que se adosa al poder por conveniencia. En ese sentido hay minorías dentro de las minorías, lugares que son triplemente segregados como lo es el travestismo. No el trasvestismo del show que ocupa su lugar en el circo de las comunicaciones, sino que el trasvestismo prostibular. El que se juega en la calle, el que se juega al filo de la calle, ese es segregado dentro del mundo gay, o también son segregados los homosexuales más evidentes en este mundo masculino. Aquí en Chile, por ejemplo, donde yo vivo que es una población, lo gay se entiende como una rara ecología, 'qué es eso', un cierto arribismo de comerse la palabrita y sustituirla por otras, de encubrir las otras categorías que han recreado tanto la homofobia como el folklore homosexual. Son palabras de agresión a lo homosexual, como el coliza o tereso, que al usarlas yo la descargo de esa energía brutal" (Entrevista realizada por Andrea Jeftanovic, 2010).

${ }^{2}$ Queer significa raro, curioso, excéntrico, amanerado; coloquialmente "maricón", "bollera”, se aplica a todos aquellos que se escapan de los parámetros heterosexuales de comportamiento y, más concretamente, a homosexuales y lesbianas. El movimiento gay se ha apropiado de este término y le ha dado un significado positivo y de resistencia. Gay, por su parte, hace referencia a la pertenencia a una clase social, raza y formación intelectual privilegiada, dentro del mundo occidental, para referirse al homosexual. Sin embargo, Kosofsky Sedgwick ha atacado la opinión de que la homosexualidad hoy "comprende un campo de definición coherente en lugar de un espacio de fuerzas definitorias en conflicto, contradictorias y sobrepuestas", para ella sería sensato trabajar desde "la relación posibilitada por la coexistencia irracionalizada de diferentes modelos durante los períodos en que existen" (1998).

3 "Los "espacios distintos", las heterotopías, siempre que superen el estadio hechizado de la utopía de la subversión, están situados dentro de un mundo social cuyas normas y tecnologías disciplinarias coaccionan, dominan y sojuzgan”. 
significados negativos. En contraste con la novela de Donoso, Tengo miedo torero (Lemebel, 2002) está escrita por un autor homosexual confeso, quien se complace en mostrar su disgusto con la norma social exhibiendo su travestismo:

Este libro surge de veinte páginas escritas a fines de los 80 , y que permanecieron por años traspapeladas entre abanicos, medias de encaje y cosméticos que mancharon de rouge la caligrafía romancera de sus letras (Lemebel, 2002).

De este modo, en el proyecto escritural de Lemebel se unen la denuncia de la marginalidad social de "la loca" con la protesta política, que es eco de la preocupación manifestada por los movimientos de liberación gay, en el sentido de unir disidencias, márgenes y desigualdades. Por su parte, El lugar sin limites, publicada en 1965, corresponde al momento en que toda la intelectualidad latinoamericana se interrogaba por sus raíces, su identidad y por la dialéctica metrópoli/marginalidad, en pleno redescubrimiento de América Latina como consecuencia del "boom". El proyecto donosiano distorsiona la mirada criollista sobre el campo chileno, invirtiendo los contenidos de ese personaje que se oponía a las fuerzas de la naturaleza, y que ahora se opone a las fuerzas conservadoras de la sociedad logrando "una visión satírica del criollismo" (Sarrochi, 1992: 123). Desde esta perspectiva, la homosexualidad de la Manuela refuerza esa mirada grotesca; es el antihéroe por excelencia, objeto de mofa y de exhibición en el pequeño caserío donde se desarrolla la historia y que, poco o nada tiene que ver con la realidad campesina, excepto para mostrar los excesos y desequilibrios del poder. $E l$ lugar sin límites le resta al campo la visión bucólica que incluía las nociones de pureza, sencillez y bondad, mostrándolo en su envés de maldad, egoísmo y crueldad.

Tengo miedo torero se inscribe en la posmodernidad, proceso en que las fronteras se diluyen para dar paso a la aldea global, agudizando el debate sobre identidades e inquiriendo fuertemente por todo tipo de marginalidad que habita la gran urbe que engulle y succiona a los individuos ${ }^{4}$. La novela de Lemebel es un tour de force porque la Loca del Frente represen-

${ }^{4}$ El personaje "la loca" puede considerarse como un nexo entre las dos novelas, que traspasa el tiempo, siendo él(ella) mismo(a) una identidad homosexual (ni gay ni travesti) sino alguien de extracción popular que a veces habla como un yo femenino y otras como un yo masculino, que a veces se viste con ropa de mujer y otras, con las de hombre. Sin embargo, la traiciona el acento, la entonación de la voz, cierto amaneramiento que siembra la duda sobre su identidad. 
ta valores auténticos, tales como amor, solidaridad, lealtad, valentía que son un contrapunto para las instituciones burguesas al desenmascarar los verdaderos rostros de la tiranía y erosionar la ilegitimidad de las prácticas homoeróticas.

Si bien, ambas novelas dan cuenta de la marginalidad del travesti, de la loca proletaria, del hijo(a) del pueblo cuyo lugar natural es el prostíbulo y/o la población, lo que las diferencia es la posición autorial de identidad con respecto de la materia narrativa.

Donoso $^{5}$ imagina la interioridad del sujeto homosexual, se apodera de su lengua equívoca, de una nueva nomenclatura para las palabras, de sus códigos paralingüísticos y sociales para representar, más que la imagen, una subjetividad distinta, maldita, otra. Aquí el lenguaje se ha liberado de la realidad: el género no se corresponde con el sexo del hablante, destruyendo la realidad referencial del cuerpo. La sexualidad de Manuel González Astica se expresa, a pesar de la hegemonía heterosexual, a través del travestismo de un cuerpo que sobrepasa su anatomía masculina y su nombre, la Manuela, se alberga en el prostíbulo, compartiendo con las mujeres un sitio infame, marginal, excluido de la sociedad.

Para la posición militante de Lemebel, el homosexual no es sólo un personaje, sino la reconstrucción de una identidad compleja, en constante lucha con el soporte material del cuerpo y con la imagen psicológica del yo. Así "la loca" discurre entre la confusión y el simulacro: los lugares comunes de la ambigüedad sexual ligados a la promiscuidad de los intercambios sexuales clandestinos y brutales. La postura de Lemebel no es diferente a

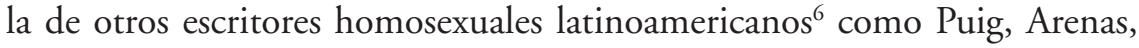
Vallejo, Sánchez, Piñera, y europeos como Guide, Proust, Genet, Cocteau, Monette, Jouhandeau, para quienes la experiencia invivible, insostenible e imposible de la homosexualidad era sinónimo de abyección y su asunción los convertía en héroes marginales que combatían contra la exclusión y la violencia de la dominación.

A continuación se analizará el uso que ambos novelistas hacen del performativo en la construcción de "la loca" y cómo se manifiesta el deseo homoerótico en ambas novelas.

${ }^{5}$ A Donoso le inquietaba que su obra fuera catalogada como "literatura gay", a tal punto que al llegar a Princeton se horrorizó al percatarse de que había tesis doctorales que lo incluían en esta línea de análisis.

${ }^{6}$ Cf. Foster (1997) La diáspora homoerótica en América Latina. 


\title{
EL USO DEL PERFORMATIVO ${ }^{7}$ EN LA CONSTRUCCIÓN DE "LA LOCA"
}

\begin{abstract}
¿Qué es lo que determina a Manuel González Astica ser mostrado como ella y no como él? ¿Hay una falla en el lenguaje que equivoca los nombres y pronombres, otorgando una sustancia diferente a los mismos cuerpos que evoca? ¿Por qué "volver loca a cualquiera” señala en dirección de un campo abyecto, a la exclusión, forclusión ${ }^{8}$ y supresión que constituyen las zonas "invivibles", "inhabitables" de la vida social? Pero al mismo tiempo, ¿`cómo el repudio a las zonas abyectas produce el espectro amenazador y a la vez seductor en la lucha constante por rearticular los significados, las prácticas y los deseos de una sexualidad inestable? En el momento en que Pancho Vega profiere: "-A las dos me las voy a montar bien montadas, a la Japonesita y al maricón del papá...” (Donoso, 1981: 10-11) no existe error al interpretar que el sujeto se refiere a tener sexo con mujeres, si bien la segunda de ellas es un hombre al cual se considera un objeto sexual femenino. Aquí no es tan importante el carácter animal, despectivo y represivo que se le da al acto sexual, sino el cómo la lengua construye un cuerpo fantasmático, que confirma la emergencia de la realidad ambigua y fundacional del "maricón": objeto de un deseo repulsivo, fantasía que surge a semejanza del hálito divino que al nombrar constituye lo nombrado y lo inaugura a la vez?
\end{abstract}

¿Podrá la Manuela sustraerse a la magia que lo nombra como el cuerpo

${ }^{7}$ Austin (1982) señala: "El acto de habla performativo (o realizativo) es aquél en el que decir algo equivale a hacer algo". Cómo hacer cosas con palabras. Barcelona: Paidós. También, Butler (2005: 315-339).

${ }^{8}$ Forclusión: Concepto elaborado por Jacques Lacan para designar un mecanismo específico de la psicosis por el cual se produce el rechazo de un significante fundamental, expulsado afuera del universo simbólico del sujeto. Cuando se produce este rechazo, el significante está forcluido. No está integrado en el inconsciente, como en la represión, y retorna en forma alucinatoria en lo real del sujeto. Cf. Chemama, R. 1998: Diccionario del psicoanálisis, Buenos Aires: Amorrortu.

${ }^{9} \mathrm{Al}$ respecto Eribon (2001) señala: "La injuria no es solamente una palabra que describe (...) El que lanza el ultraje me hace saber que tiene poder sobre, que estoy a su merced. (...) La injuria es un acto de lenguaje - o una serie repetida de actos- por el cual se asigna a su destinatario un lugar determinado en el mundo. Esta asignación determina un punto de vista sobre el mundo, una percepción particular. La injuria es un enunciado performativo: su función es producir efectos y, en especial, instituir o perpetuar la separación entre los 'normales' y aquellos a los que Goffman llama los 'estigmatizados', e inculcar esta grieta en la cabeza de los individuos. La injuria me dice lo que soy en la misma medida en que me hace ser lo que soy"(30-31). Por su parte, Bourdieu, en La dominación masculina señala: "Los dominados aplican a las relaciones unas categorías construidas desde el punto de vista de los dominadores, haciéndolas aparecer de ese modo como naturales" (2001: 50). Esta "dominación masculina" se puede entender no sólo de los hombres sobre las mujeres, sino de un modo más general de dominación: "el principio masculino" sobre el "principio femenino", que estaría cobijando a los homosexuales. 
que no es, pero que le confiere identidad por repetición, por desprecio, por exclusión? Este cuerpo que no se corresponde con su nombre necesita de objetos externos que funcionan como performativos: el traje de la manola, "un vestido colorado con lunares blancos", "el chal rosado" que coloca sobre sus hombros, "las plumas lloronas": todos elementos constitutivos del garabato, que al borronear los rasgos viriles, crean la ilusión de lo femenino que dura el instante fugaz de lo que demora Pancho en pronunciar "me las voy a montar bien montadas" para desmoronarse en el significado de la palabra "maricón".

En efecto, la Manuela se crea en la ilusión y la desilusión, inventándose y dejándose inventar en distintos papeles: travesti, padre, propietaria. El vestido y todas las prendas femeninas que usa tienen un carácter performativo, pues como señala Butler el travestismo es un ejemplo de performatividad. Las implicaciones teóricas de esta afirmación son más profundas y conflictivas porque, para ésta, el travestismo constituye una postura subversiva "en la medida que refleja las personificaciones mundanas mediante las cuales se establecen y naturalizan los géneros ideales desde el punto de vista heterosexual y que socava el poder de tales géneros al producir esta exposición", pero resulta problemático porque "nada garantiza que exponer la condición naturalizada de la heterosexualidad baste para subvertirla, (...) cuando vemos (que) esas parodias de desnaturalización reidealizan las normas heterosexuales sin cuestionarlas" (Butler, 2005: 224-225).

El ponerse el vestido constituye para la Manuela un acto performativo y transgresor, a la vez, porque al afirmar un sexo que no tiene exacerba los deseos ocultos de la comunidad masculina, provocando la lujuria que se inscribe como una trizadura en la tersa superficie del deseo heterosexual.

Me dan ganas de ponerme el vestido delante de él para ver lo que hace. Ahora, si estuviera aquí en el pueblo, por ejemplo. Salir a la calle con el vestido puesto y flores detrás de la oreja y pintada como mona, y que en la calle me digan adiós Manuela, por Dios que va elegante mijita, quiere que la acompañe... Triunfando una (31).

Y desde el momento en que la Manuela se siente posicionada como mujer, comienza a soñar con el "príncipe azul" de las mitologías femeninas y a sustituir su linaje canalla, su filiación marginal con un nombre ganado en el "arte":

... que yo soy gente más decente que él, que al fin y al cabo no es más que 
hijo de un inquilino mientras que yo soy la gran Manuela, conocida en toda la provincia, y echa a Pancho para siempre del pueblo. Entonces Don Alejo me sube al auto y me lleva al fundo y me tiende en la cama de Misia Blanca, que es toda de raso rosado dice la Ludovina, preciosa (32).

Desde la aproximación que plantea Butler, se entiende que la fantasía de la Manuela busca la normalización de su condición parasitaria, abyecta e incómoda porque todas sus fantasías tienen que ver con el ideal heterosexual blanco y con una posición social dominante: (el)la protagonista(o) se siente más que inquilino(a) y se iguala con la oligarquía terrateniente:

...mientras misia Blanca me pone compresas y me hace oler sales y me toma en brazos y me dice mira Manuela, quiero que seamos amigas, quédate aquí en mi casa hasta que te sanes y no te preocupes, yo te cedo mi pieza y pide lo que quieras, no te preocupes, no te preocupes ... (33).

Algo semejante ocurre con la Loca del Frente, que antes de conocer al revolucionario se identifica con el gobierno militar, borda para las esposas de los generales y se considera bien tratada cuando la dejan esperando en la cocina. Recibida por la puerta de servicio, relegada al lugar de la casa que ocupa la servidumbre y donde se realizan las actividades insignificantes de la sociedad, la protagonista experimenta también la misma transustanciación de género que la Manuela, pues ambas buscan el hombre que ostente un sitio privilegiado en la sociedad y que sea la promesa de un refugio contra la homofobia y la miseria ${ }^{10}$. Para la Manuela este hombre será don Alejandro Cruz: hombre blanco, senador de la República y dueño de El Olivo; en el caso de la Loca del Frente, los militares que se han apoderado del gobierno, mediatizados por sus esposas para quienes ella(el) borda "servilletas, manteles y sábanas con punto cruz, con bolillo, con deshilado y naveta".

Sin embargo, la distancia temporal que separa a ambos(as) protagonistas establece diferencias fundamentales; la Manuela se produce como el cuerpo fantasmático de la mujer, pero su travestismo es una parodia no crítica de la hegemonía heterosexual pues los actos de catacresis del habla evidencian una referencia vacía o errada que pone en tela de juicio la función aparente del nombre propio. El uso inapropiado del nombre apropiado contribuye

${ }^{10}$ Según Seidman "el status de orientación sexual posiciona al yo en la periferia o el centro sociales; lo sitúa en una relación determinada con los recursos institucionales, las oportunidades sociales, las protecciones legales y los privilegios sociales; lo pone en relación con una serie de forma de control social, desde la violencia hasta el ridículo". Citado por Bersani, 1998: 84. 
a la decepción que experimenta la Manuela cada vez que los hombres cautivados por el baile, seducidos por su falsa femineidad y atrapados por un deseo sexual prohibido reniegan de él, agrediéndola, haciéndola objeto de sus golpes, salivazos y humillaciones:

Se acercó el Encargado de Correos y le arrebató la Manuela a don Alejo. Alcanzaron a dar una vuelta a la pista antes de que el Jefe de Estación se acercara a quitársela y después otros y otros del círculo que se iba estrechando alrededor de la Manuela. Alguien la tocó mientras bailaba, otro le hizo una zancadilla. El viñatero jefe de un fundo vecino le arremangó la falda (...). Le tocaban las piernas flacas y peludas o el trasero seco, avergonzados, ahogándose de risa (105-106).

Se puede observar, que quienes se acercan a la Manuela no son individualidades, sino personajes-etiquetas: el Encargado de Correos, el Jefe de Estación, el viñatero jefe, todos funcionarios de un orden social ${ }^{11}$ que es desbordado por el baile de la Manuel(a) y que para retornar a sus límites debe castigar al pervertido, al monstruo, al anormal:

Y lanzaron a la Manuela al agua. Los hombres que la miraban desde arriba, (...) se ahogaban de risa, señalando a la figura que hacía poses y bailaba, sumida hasta la cintura en el agua, con el vestido flotando como una mancha alrededor suyo y cantando "El relicario".(...) Uno de los hombres trato de mear a la Manuela, que pudo esquivar el arco de la orina (107).

En este sentido, los personajes-etiquetas sancionan el desafío de la $\mathrm{Ma}$ nuela, su pretensión de naturalidad, su reclamo de originalidad, que forman parte de los privilegios de la heterosexualidad ${ }^{12}$. Y es por esta razón que el lector puede predecir el desenlace novelesco: el lugar sin límites, la tierra de nadie, este rincón neutro donde cielo e infierno se confunden, donde la

${ }^{11}$ Personajes que pueden permitirse este recreo en el espacio privado del prostíbulo e, incluso, aprovechar su condición "masculina” para a través de la injuria, la burla y la violencia negarlo y restablecer el orden, que subvierte "el maricón" con su exhibición. Se puede trasvolar la cita de Eribon (2001) del artículo de Kososfsky Sedgwick, "Queer performativity”, “...este juego que se hace con la presentación de uno mismo: el "apartarse", el estado de ser "aparte" engendra en muchos homosexuales una vida interior llena de imágenes y fantasmas (sacados de los libros, de películas, de revistas, de personajes vistos...) que exteriorizan como sus propios gestos, su teatro personal, cuando se deciden a hacer público el secreto que les hacía interpretar el "juego" de la discreción y la imitación de los modos heterosexuales (150).

12 "...el privilegio heterosexual opera de muchas maneras y dos de ellas son naturalizarse y afirmarse como lo original y la norma”, Butler (2005:185). 
Manuela despliega sus estrategias de seducción, sus artificios, su parodia; este espacio constituye el escenario en el que se lee la divergencia entre el cuerpo representado y su representación. La amenaza homosexual se conjura con la muerte de la Manuela ${ }^{13}$. Sin embargo, ¿se puede creer que El lugar sin límites forme parte de aquellos textos que al provocar la decepción de la protagonista y la desidentificación del lector sólo pretende la perpetuación de la norma heterosexual? Una lectura planteada en estos términos negaría los efectos que provocan las hegemonías de clase, sexo y/o razas, celebrando la opresiones y naturalizando la violencia; si bien es cierto, que la Manuela en su búsqueda de la promesa fantasmática de un cuerpo que debiera proporcionarle los mismos privilegios que a las mujeres, obtiene, precisamente por el uso de su masculinidad, un lugar propio y una hija no deseada, que le representa un cuerpo que se niega a ser colonizado y tratado como mercancía, en la economía del intercambio sexual:

Era un fenómeno. Y después decía que no. Que no quería que la anduvieran mangoneando. Que ya que era dueña de la casa de putas mejor sería que ella también fuera puta. Pero la tocaba un hombre y salía corriendo (30).

La hija de la Manuela prefiere otro tipo de intercambio, ser capitalista, explotar a otras mujeres para conseguir, por ejemplo, el sueño del Wurlitzer. La Japonesita se pone al servicio del deseo heterosexual, administrando una casa de prostitución, pero sacrificando su propio deseo:

Sí, si Pancho Vega no fuera tan bruto entonces ella se enamoraría de él y sería su amante un tiempo hasta que la dejara para irse con otra, porque así son de brutos los hombres, y después yo sería distinta. $\mathrm{Y}$ tal vez no tan avara, (...), tan amarrada con mi plata (...). Y yo tal vez no sentiré tanto frío. Un poco de dolor o amargura cuando el bruto de Pancho se fuera, pero qué importaba, nada, si ella, y ella también, quedaba más clara (68).

Sin embargo, existe una correspondencia entre ambas: el deseo de fama regional y nacional de la Manuela es al deseo del Wurlitzer de la Japonesita

${ }^{13}$ Según Butler, el travestismo presente en algunos filmes como Victor, Victoria, Tootsie, Una Eva y dos Adanes "cumple la función de suministrar un alivio ritual a la economía heterosexual que debe vigilar constantemente sus propias fronteras contra la invasión de lo que esta producción y resolución desplazada del pánico homosexual realmente fortalece el régimen heterosexual en su tarea de autoperpetuarse (2005: 185). 
del mismo modo que el deseo de un cuerpo femenino es a la erotización del cuerpo neutro de su hija. Estas analogías no son ajenas al(a la) protagonista de la novela de Lemebel, la Loca del Frente que también transita el ámbito espectacular de su travestismo: bailar para los hombres, para su diversión al igual que bordar para el bienestar y goce del patriarcado no constituyen acciones tan diferentes, pero sin embargo marcan la distancia entre las dos novelas y el estatuto del homosexual en la sociedad de las épocas representada en los textos. En los alrededores de los años 50, el lugar del travesti estaba en el prostíbulo; en los años 80 queda encerrado además en las poblaciones marginales. Sólo matones, ladronzuelos, asesinos, gentes de mal vivir podían acoger al homosexual pobre y permitirle una existencia menos traumática. Más aún, en El lugar sin límites, la muerte de la Manuela como desenlace novelesco apunta a las ocasiones "en las que la condición ficticia e inestable de ese yo corporal perturba el nombre, lo expone como una crisis en la referencialidad" (Butler, 2005: 202); ahora el nombre de la Manuela designa la incertidumbre del género, pero también una crisis en la figuración de la morfología sexuada:

Parada en el barro de la calzada mientras Octavio la paralizaba retorciéndole el brazo, la Manuela despertó. No era la Manuela. Era él, Manuel González Astica. Él. Y porque era él iban a hacerle daño y Manuel González Astica sintió terror (175).

El nombre en femenino de la Manuela así como los pronombres femeninos con los que la Loca del Frente se refiere a sí misma(o) constituyen una desestabilización del género y la sexualidad, que en El lugar sin límites será castigada con la muerte y la decepción de la propia Manuela, dado que la promesa del espacio seguro, delimitado, sin culpa cede su sitio al lugar sin límites de la orfandad, de la concretización siempre pospuesta, frágil e imposible de un sexo que no es y que no está, pero que es necesario para los intercambios mercenarios de la economía sexual.

... pero tenía que seguir corriendo porque don Alejo le prometió que le iba a ir bien, que le convenía, que nunca más iba a sentir el peso de lo que sentía antes si se quedaba aquí donde estaba él, era promesa, juramento casi, y se había quedado y ahora lo venían persiguiendo para matarlo. Don Alejo, don Alejo (...) Decirle por favor, defiéndame del miedo, usted me prometió que nunca me iba a pasar nada que siempre iba a protegerme y por eso me quedé en este pueblo y ahora tiene que cumplir su promesa de 
defenderme y sanarme y consolarme, nunca antes se lo había pedido ni le había cobrado su palabra pero ahora sí, sólo usted, sólo usted... $(176,177)$.

En Tengo miedo torero, el(la) protagonista no tiene que pagar con su vida la condición abyecta y vergonzante de su sexualidad; por esta razón la novela puede leerse como la reterritorialización de un término que fue utilizado para excluir a un sector de la población. No obstante, las semejanzas ya señaladas, la novela de Lemebel intenta dar una resignificación social y política a la homosexualidad. En la medida que la Loca del Frente es un travesti, hiperboliza las normas de la femineidad para constituirse como sujeto de manera provocativa frente a la hegemonía heterosexual y a su paradigma, la dictadura militar de Chile en el período 1973-1990.

En esta perspectiva, la novela construye la identidad de "la loca" a partir del lenguaje más que del vestido, como ocurría con la Manuela. Desde las primeras páginas, el narrador adopta un tono teatral en el que se funden la canción popular, los medios de comunicación y la voz que modula la "rareza”, la indeterminación sexual, el acento recargado, en el que no se reconoce un hablante masculino o femenino:

Así, cual abejorro zumbón, iba y venía por la casa emplumado con su estola de: Sí Carlos. No Carlos. Tal vez Carlos. A lo mejor Carlos. Como si la repetición del nombre bordara sus letras en el aire arrullado por el eco de su cercanía. Como si el pedal de esa lengua marucha se obstinara en nombrarlo, llamándolo, lamiéndolo, saboreando esas sílabas, mascando ese nombre, llenándose toda con ese Carlos tan profundo... (Lemebel, 2002: 11).

Ya no es el chal o el vestido de manola los encargados de crear el reflejo de otro cuerpo, sino la lengua marucha y la relación con el otro lo que le confiere identidad y que a diferencia de la Manuela se produce en la interioridad de la Loca del Frente. La voz de la Loca del Frente aparece como la "estola", el eco flotante de las ondas sonoras de un nombre que la define como la mujer que no es, pero que se siente atraída por otro hombre. Del mismo modo el espacio que la contiene es solidario en su geografía con el cuerpo endeble y frágil del "maripozuelo" y las tareas que desarrolla para su supervivencia: bordado de manteles y sábanas. Inmerso en el "medio pelo" santiaguino, sobrevive a la agitación política de la década de los ochenta con la música del recuerdo: boleros y cuplés que ignoran la contingencia del momento. En una primera aproximación, la Loca del Frente es un cuerpo en el 
que no quedan huellas de los cambios hormonales de la pubertad: la voz no ha enronquecido y sigue caminando "sobre huevos" a pesar de los intentos por disciplinar este cuerpo a través de la escuela y la medicina:

Del colegio lo mandaron a llamar varias veces para que me viera un psicólogo, pero él se negaba. La profesora decía que un médico podía enronquecerme la voz, que sólo un médico podía afirmar esa caminada sobre huevos, esos pasitos fi-fi que hacían reír a los niños y le desordenaban la clase (16).

Pero también es el cuerpo abusado por la prepotencia de los que ejercen el poder, el territorio sobre el cual, la "patria potestad", la tiranía, el machismo, la heterosexualidad, etc., ejercen su dominio. El relato de la agresión no es una explicación de las causas de la homosexualidad; la Loca del Frente asume su violación como otro ejemplo de sexo triste y sin consecuencias, que parecieran ser la tónica de los encuentros sexuales prohibidos, y el hecho que el autor de la tropelía sea el propio padre, constituye el primer encuentro entre el débil y el fuerte, entre la hegemonía y la marginalidad, entre la legalidad burguesa y el infractor, si bien no alcanza a despertar en el violentado otra cosa que no sea la tristeza y un recuerdo amargo en el que no logra reconocer los ingredientes de la exclusión, del menosprecio y de la discriminación:

Tan ardiente su cuerpo de elefante encima mío punteando, ahogándome en la penumbra de esa pieza, en el desespero de aletear como pollo empalado, como pichón sin plumas, sin cuerpo ni valor para resistir el impacto de su nervio duro enraizándome (16).

Esta experiencia límite se inscribe en su cuerpo y en su inserción en el mundo; la segregación, la injuria y el desprecio actúan performativamente sobre el homosexual, lanzándolo fuera de los límites soportables de lo humano, al decir de Genet: "la psicología del oprimido la decide el opresor".

El encuentro de la Loca del Frente con Carlos reconfigura esta identidad inestable porque le permitirá "enrielar su corazón golondrino" (Lemebel, 2002: 15) y tomar conciencia del lugar marginal que siempre le ha correspondido en la sociedad autoritaria de la dictadura. De la indiferencia que le producen las noticias relacionadas con los actos de rebeldía de la población en contra de Pinochet, la Loca del Frente se sumerge en un plan cuyo centro 
es la caída y muerte del dictador, un juego de apariencias en el cual su ambigüedad es crucial para el proyecto de los rebeldes. La casa ruinosa permite la trasmutación de las sospechosas cajas en muebles, mesas y sillones que acoge por igual la humanidad de las amigas maricas y la de los revolucionarios. El sentido de pertenencia a una clase social que carece de privilegios despierta en forma paulatina; primero, las mujeres que claman por los desaparecidos y luego, la visión de los generales en una verdadera orgía de sangre sobre los ángeles y pajaritos bordados en sus manteles:

En su cabeza de loca enamorada el chocar de las copas se transformó en estruendo de vidrios rotos y licor sangrado que corría por las bocamangas de los alegres generales. El vino rojo salpicaba el mantel, el vino lacre rezumaba en manchas de coágulos donde se ahogaban sus pajaritos, donde inútilmente aleteaban sus querubines como insectos de hilo encharcados en ese espeso festín (65).

De esta forma, Tengo miedo torero es el relato de la construcción de una identidad que no tiene un soporte corporal, ignorante de las relaciones complejas de inclusión y exclusión donde el "maricón" del barrio ocupa el lugar de la abyección, de lo monstruoso, del tabú sexual. Esta percepción primaria omite otros atributos como raza, clase que también crean la diferencia, los lugares de opresión del heterosexismo cristiano occidental. Lo inconcebible para la humanidad heterosexual tiene lugar en este cuerpo, en la psiquis que no se corresponde con los genitales masculinos, en esta asimetría que es necesario corregir sin importar el deseo del sujeto; por esta razón es posible que el texto novelesco de Lemebel inaugure "una narrativa que interrogue los límites concebibles de lo humano. Lo que es inconcebible se concibe una y otra vez, a través de medios narrativos, pero algo permanece en el exterior de la narrativa, un momento de resistencia que señala la persistencia de la cualidad del ser inconcebible" (Butler, 2006: 99). No sólo Tengo miedo torero sino que todos los textos de Lemebel son un llamado al reconocimiento de una sexualidad instalada en los márgenes de la existencia social: lo inconcebible, lo indecible, lo insoportable, lo invivible, etc., en fin todo aquello que la hegemonía heterosexual considera susceptible de normalizar mediante la cirugía, la cura psiquiátrica y la administración de hormonas para inducir artificialmente una "naturalidad" que la naturaleza misma se ha negado a crear.

De acuerdo con Butler, lo único persistente dentro de esta sexualidad 
inestable es la "materialidad"14 del cuerpo, que es un algo innegable que condiciona el comportamiento de Manuel(a) y de la Loca del Frente; para la primera, el vestido construye su identidad femenina en tanto que para la segunda su identidad descansa en el amor por otro hombre, en la invención de una lengua que autoriza nombrar lo mismo con otras palabras y escaparse de los modelos prescritos por la heterosexualidad.

\section{EL DESEO HOMOERÓTICO EN LA MANUELA Y EN LA LOCA DEL FRENTE}

A pesar de las semejanzas entre las dos novelas existen algunas diferencias referidas al deseo sexual y a sus codificaciones en los dos textos. La estructura novelesca, su inserción en un determinado canon literario, la homosexualidad confesa o no del autor determinan las topologías del homoerotismo. Todas las manifestaciones de la sexualidad de la Manuela confirman la fuerza del performativo "maricón" y la importancia que el "chal" y el "vestido de manola" tienen en la configuración de la identidad sexual. En la década de los cincuenta los tabúes sexuales, sociales y religiosos gobernaban las relaciones; la sexualidad marginal estaba adscrita a las significaciones que el binarismo heterosexual asignaba a lo femenino, es decir, en el lugar subalterno de esa sexualidad normada: así el homosexual o "la loca" se sitúa al lado de ésta, en el prostíbulo, punto de fuga de los placeres masculinos, como otro cuerpo dispuesto a la satisfacción de los hombres.

En este sentido, la Manuela constituirá la parodia de la mujer y colocada en la jerarquía heterosexual, estará un lugar más abajo, degradado en su integridad por atreverse a buscar el placer reservado sólo a las mujeres. No es extraño, entonces, que la Manuela utilice las mismas artes de seducción femeninas, pero deformadas de antemano porque aún en el prostíbulo él(ella) es una caricatura que se produce para el instante fugaz en que la proliferación de signos da a los otros la ilusión de su femineidad. La novela de Donoso no sólo deconstruye el ideal de una ruralidad bucólica y apacible, sino también las garantías de la unión heterosexual, vista como el "final feliz" hacia donde discurre el amor de los relatos maestros de la literatura

${ }^{14}$ Cf. Butler (2005: 107-108) Al respecto Butler hace un análisis de la materialidad del cuerpo desde el punto de vista fenomenológico y desde el punto de vista kantiano. En las novelas esta "materialidad" constituye el sustento concreto que cada novela aborda de diferentes maneras. 
cristiana occidental. Es así que la contraparte del cielo ${ }^{15}$ es este lugar infernal, de perdición y lujuria, donde los hombres descubren nuevos placeres que contravienen el paradigma de la sexualidad monógama destinada a la procreación. En el prostíbulo dan rienda suelta a sus fantasías, pero también los parroquianos controlan los deseos de los otros(as); así, la Manuela objeto sexual aunque diferente refleja, en un espejo abismal, los deseos prohibidos de don Alejo, el jefe de estación, de correos, el viñatero jefe, etc. Es en este juego donde perversamente los hombres se prestan para ser objeto de deseo de la Manuela, conservando el estatuto de marioneta que éstos y sobre todo el poderoso don Alejo le han concedido.

Alguien la tocó mientras bailaba, otro le hizo una zancadilla. El viñatero jefe de un fundo vecino le arremangó la falda y al verlo, los que se agrupaban alrededor para arrebatarse a la Manuela, ayudaron a subirle la falda por encima de la cabeza, aprisionando sus brazos como dentro de una camisa de fuerza. Le tocaban las piernas flacas y peludas o el trasero seco, avergonzados, ahogándose de risa (Donoso, 1981: 106).

Dos reflexiones surgen al respecto; la primera tiene que ver con las elaboraciones mentales de la Manuela sobre sí misma: desea a los hombres genéricamente "le gustaban todos, cada uno en su estilo" unido a la autoconciencia de un cuerpo deteriorado, desdentado; la segunda se relaciona con el cuerpo ortopédico con que la sociedad la inmoviliza, el vestido convertido en "camisa de fuerza" que lo obliga a comportarse como un monigote o seguir los estereotipos que el sexo hegemónico le asigna para su satisfacción.

Es interesante comprobar que la novela de Donoso narra desde la periferia los sentimientos de la Manuela porque ella misma está sumida en la teatralidad de su conducta: "triunfando, una", "ella saldría vestida de manola", "y que en la calle me digan adiós Manuela, por Dios que va elegante mijita”. Incluso cuando se teatraliza la relación sexual con la Japonesa, lo narrado corresponde a la forma en que la Japonesa supone que tendría que ser una relación homosexual entre dos mujeres. En resumen, El lugar sin límites es una de las primeras novelas que coloca el tema de "la loca" en el lugar de los llamados placeres "queers" para la heterosexualidad, sin reidealizar la norma sexual hegemónica, que impugna por su violencia, intolerancia y dogmatismo:

${ }^{15}$ En numerosos estudios que se han hecho sobre El lugar sin límites, el prostíbulo aparece como uno de los lugares infernales de El Olivo, entre ellos podemos citar a Cánovas (2000). 
No alcanzó a moverse antes que los hombres brotados de la zarzamora se abalanzaran sobre él como hambrientos. (...) tal vez no fueran ellos, sino otros hombres que penetraron la mora y se lanzaron sobre él y lo patearon y le pegaron y lo retorcieron, jadeando sobre él, los cuerpos calientes retorciéndose sobre la Manuela que ya no podía ni gritar, (...) los tres una sola masa viscosa, (...) unidos los tres por el vómito y el calor y el dolor allí en el pasto, buscando quién es el culpable, castigándolo, castigándola, castigándose deleitados hasta en el fondo de la confusión dolorosa... (Donoso, 1981: 178).

Si bien el desenlace de la novela constituye una condena a la sexualidad prohibida cuyo castigo es la muerte, este rechazo aparece inseguro, inestable, confuso tanto en la conciencia de la Manuela como en la de su hija, la Japonesita. En su abandono semiinconsciente junto al río, el(ella) cree que del otro lado "Don Alejo espera benevolente", dejando la vaga ilusión de un perdón que tampoco se concreta. La Japonesita, en cambio, supone que la salida de su progenitor es una más entre otras y que tarde o temprano reaparecerá "con un ojo en tinta o un par de costillas quebradas". Esta vacilación evita asumir la muerte de la Manuela y, al mismo tiempo, muestra una posición autorial ambigua o neutra que no resuelve el repudio ni tampoco la aceptación de la homosexualidad, dado que la muerte de "la loca" constituiría otra forma de normalización, de supresión de lo monstruoso, de eliminación de lo anormal.

La novela de Lemebel tiene una doble connotación: por una parte está escrita con la intención de corroer el proyecto de Reconstrucción Nacional del Gobierno Militar que se instaura en Chile en 1973 y por otra, socavar la hegemonía de la norma heterosexual instalando en el texto las claves del deseo homoerótico. A través de la literatura se construye el imaginario social, se reproducen los roles sexuales y se perpetúa el poder; de ahí la importancia que adquiere la "lengua marucha"16 en la producción de una nueva sensibilidad que acoge este deseo sin enmascararlo, en una doble vertiente: a través del lenguaje soez, directo e intimidante y de un lenguaje poético, que intenta vaciar de sus significaciones demoníacas, marginales e insoportables este deseo erótico que se inscribía en la esfera de lo indecible, imposible e invivible de la existencia de algunos seres. Este poder de decir, de expresar un deseo constreñido por la materialidad del cuerpo, por la norma hetero(2005).

${ }^{16} \mathrm{Al}$ respecto, véase mi artículo "Tengo miedo torero, de Pedro Lemebel: ruptura y testimonio" 
sexual y por la ideología cristiana de Occidente construye sus significantes sobre la anatomía de un cuerpo semejante, que adquiere por esa mirada otros significados que, deseados o no, se incorporan a la realidad deseante ${ }^{17}$ :

No lo pensaba, ni lo sentía, cuando su mano gaviota alisó el aire que la separaba de ese manjar, su mano mariposa que la dejó flotar ingrávida sobre el estrecho territorio de las caderas, sus dedos avispas posándose levísimos en el carro metálico del cierre eclair para bajarlo, para descorrerlo sin ruido, con la suavidad de quien deshilacha una tela sin despertar al arácnido (Lemebel, 2002: 106).

Siguiendo las aproximaciones teóricas de Butler, la persistencia del ser inconcebible pertenece a una conciencia externa que bien puede ser el lector o incluso el mismo personaje, que actúa este deseo por el otro cuerpo o que intenta vivir una experiencia en el límite de lo imposible. De este modo, la Loca del Frente tiene que reinventar la lengua del amor carnal, producir la ilusión para ella misma de un cuerpo preparado para su satisfacción y goce, escribir sobre lo ya escrito otro código, sobreponer significados para significantes ya construidos. El deseo homosexual tiene que borronear su inventario sobre los signos establecidos:

Las mujeres no saben de esto, supuso, ellas sólo lo chupan, en cambio las locas elaboran un bordado cantante en la sinfonía de su mamar. Las mujeres succionan nada más, en tanto la boca-loca primero aureola de vaho el ajuar del gesto. La loca sólo degusta y luego trina su catadura lírica por el micrófono carnal que expande su radiofónica libación. Es como cantar... (Lemebel, 2002: 108).

Este inventario se construye sobre la percepción homosexual de los genitales masculinos y aunque pertenece a un registro poético, no intenta imitar el canon literario ni la tradición que existe acerca del cuerpo femenino en la

${ }^{17}$ Butler, en Deshacer el género, señala: "Este cuerpo se convierte en punto de referencia para una narrativa que no trata de este cuerpo, pero que se abalanza sobre el cuerpo, por así decirlo, con el fin de inaugurar una narrativa que interrogue los límites concebibles de lo humano. Lo que es inconcebible se concibe una y otra vez, a través de los medios narrativos, pero algo permanece en el exterior de la narrativa, un momento de resistencia que señala la persistencia de la cualidad del ser inconcebible" (Butler, 2006: 99). Por otro lado en el texto citado de Tengo miedo torero se puede estudiar la simbología de la "mano gaviota", "mano mariposa" y las relaciones que se pueden establecer con el "arácnido". Este análisis semántico mostraría la intención de mostrar el juego de seducción que se establece entre la presa, cazador-cazado, y la lúdica mariposa. 
lírica: v.gr., el miembro viril en reposo es un "muñón veinteañero", "lagarto somnoliento", "tronco blando", "bebé en pañales", "nene en reposo", "saurio enguantado", "guagua-boa", "guarisapo, en contraste con "perno carnal", "robustez de un trofeo de guerra", "hongo lunar" del miembro erecto. Este campo semántico corresponde a un cuerpo masculino erotizado y convertido en objeto poético, tal como por siglos lo ha sido el cuerpo de la mujer. $\mathrm{Al}$ respecto, cabe señalar algunas diferencias; las metáforas son burdas comparadas con el repertorio que la lírica ha acumulado sobre el cuerpo femenino. Los órganos sexuales femeninos, aunque no constituyen el tópico más frecuente, son metaforizados como "cavernas", "colinas", profundidades" y generalmente se asocian a la geografía terrestre. Las manos, los ojos, el cabello, los senos, los muslos han sido siempre elementos recurrentes con los que se intenta celebrar la belleza femenina. En cambio, en la poética del deseo homoerótico las asociaciones se relacionan con el mundo animal, especialmente con los reptiles ${ }^{18}$. Esta relación con lo innoble se puede asociar con otros textos de Lemebel, en que escribe sobre el sentimiento de inferioridad que experimentan los homosexuales por su preferencia sexual ${ }^{19}$; sin embargo, es más seguro conjeturar sobre el linaje canalla de la lengua "marucha", dado que debe modelar desde el prostíbulo las experiencias de la relación interdicta, que recoge de los barrios marginales de la metrópoli las metáforas que nombran al "maricón": "cola", "mariposa" y que son incorporados al texto con el fin de menoscabar los significados infamantes: "mano mariposa" que literalmente sería "mano maricona", "niño colibrî", equivalente a niño cola, "acento marifrunci de su voz", "yegua coliflor" y tantos otros sintagmas que ofrecen resistencia al significado degradante, al mismo tiempo que resti-

${ }^{18}$ A la asociación de los órganos sexuales masculinos con los reptiles le adjudicaremos la simbología correspondiente a la serpiente, según el psicoanálisis: “ un vertébré qui incarne la psyché inferieure, le psychisme obscur, ce qui est rare, incompréhensible, mystèriex" ("un vertebrado que encarna la psiquis inferior, el psiquismo oscuro, lo que es raro, incomprensible, misterioso". La traducción es mía) en Chevalier y Gheerbrant (1982).

${ }^{19}$ Véanse los textos de Lemebel que hablan sobre el menosprecio que la sociedad siente por aquellos que nacen con "la alita rota", especialmente, el "Manifiesto" leído en septiembre de 1986, Santiago, y posteriormente recopilado en Loco Afán. Crónicas de sidario (1994). Al respecto, Eribon (2004: 297) señala: "Ya no se trata de saber cómo y por qué se llega a ser 'homosexual' y por qué, cuando se es homosexual no se quiere cambiar, sino considerar que serlo es estar inscrito por el orden social en una categoría considerada inferior, expuesta al insulto, la infamia, la abyección... no hay una etiología individual de los psiquismo que conduzca a la homosexualidad, sino estructuras poco igualitarias del orden social que colocan a determinados individuos en categorías interiorizadas, condenadas, sometidas al ostracismo (ser mujer, ser homosexual, ser negro, etc.), y el hecho de pertenecer a una de esas categorías produce un tipo de psiquismo que no depende de eso a lo que la verborrea psicoanalítica nos tiene acostumbrados, sino de la violencia social y de las estructuras de la dominación". 
tuyen al signo su arbitrariedad perversa, su poder de sortilegio, su capacidad subversiva ${ }^{20}$.

Este análisis no puede olvidar el lenguaje soez, directo e intimidante que cumple un papel dentro de la política destinada a desestabilizar la norma heterosexual. Este lenguaje desenfadado, brutal, que desafía la represión, es un foco de resistencia que invita a los individuos a constituirse en sujetos ${ }^{21}$, a inventarse a sí mismos como sujetos libres, haciendo visibles los signos de la opresión:

Su son maraco al vaivén de la noche, al vergazo oportuno de algún ebrio pareja de su baile, sustento de su destino por algunas horas, por algunas monedas, por compartir ese frío huacho a toda cacha caliente. A todo refregón vagabundo que se desquita de la vida lijando con el sexo la mala suerte (Lemebel, 2002: 15).

No obstante, la novela no muestra el deseo homosexual de la burguesía intelectual y acomodada, sino el de "la loca" pobre, que no habita el prostíbulo sino que se refugia en los márgenes de la ciudad, en las barriadas y poblaciones marginales. Siguiendo las categorías de Eribon ${ }^{22}$ (2001), el sujeto de la enunciación construye un "discurso del rechazo" o contradiscurso que no necesariamente es un discurso contrario, sino el mismo cuyos significados se invierten: la relación sexual ya no puede entenderse como la unión de cuerpos de diferente sexo, como tampoco el comercio sexual: "no faltaría el roto que le moliera el mojón por un plato de comida”. Esta forma descarnada, vulgar y acaso feroz, evidencia el deseo sexual de "la loca" de ser penetrado, a la vez que desexualiza los contenidos eróticos convirtiéndolos en "un plato de comida", satisfacción de otro de los apetitos primarios y diseminación del deseo sexual al resto de los sentidos: fruición, deleite y concupiscencia. Esta desexualización no implica una heterosexualización de la homosexualidad ${ }^{23}$ sino más bien la resistencia a la normalización y

${ }^{20}$ Sin embargo, habría que distinguir la voz del deseo asociada al mundo animal, reptiliano, de la "lengua marucha" poética que se asociaba al mundo vegetal, como una forma de romper con la tradición e instalar una nueva forma de expresión para el sentimiento homosexual. Véase mi trabajo en Estudios Filológicos 40, pp. 121-129.

${ }^{21}$ En el sentido utilizado por Gilles Deleuze, "Sur la philosophie" (1990: 206), la subjetivación sería "la operación por la cual individuos o comunidades se constituyen como sujetos al margen de los saberes constituidos y los poderes establecidos”. Cf. Eribon (2001: 473).

${ }^{22}$ Cf. Eribon (2001: 431-443), se trata de dar un nuevo significado a un enunciado o a un discurso con el fin que un individuo pueda transformarse y reinventarse.

${ }^{23}$ Cf. Con el análisis de Leo Bersani sobre la obra de Proust, como el intento de heterosexualización de la homosexualidad en Homos, cap. 3 "El gay fuera de la ley" (1998: 150-170). 
cartografía de los placeres sexuales diseñados por la norma hegemónica ${ }^{24}$. El lenguaje grosero, desafiante y provocativo invierte el sentido del acto sexual, transforma su productividad en un desecho del cuerpo ("moliera el mojón"), que luego será expulsado al exterior, no importando el amor o los sentimientos: el deseo homoerótico es un deseo anónimo, donde sólo cuenta el placer o la satisfacción ${ }^{25}$ :

Así de ebrios, y sin un peso, era fácil para sus amigas arrastrarlos hasta el caserón, y luego adentro rebalsarlos de vino tinto y terminar las tres a poto pelado compartiendo las caricias babosas del caliente hombrón. (...) En esa casa siempre había algún hombre dispuesto a deshollinar algún orto ${ }^{26}$ desconocido. (...), todas dormimos tranquilas, (...) porque cada noche no nos falta el pichulazo para soñar con los angelitos (Lemebel, 2002: 75-76).

En el trayecto novelesco de Tengo miedo torero, el deseo homosexual además de su anonimato se caracteriza por su precariedad y oportunidad; nada garantiza la correspondencia entre satisfacción sexual y sentimiento amoroso. En la Loca del Frente se siente la vulnerabilidad, el estado de indefensión y pesadumbre que le provocan sus sentimientos por Carlos:

...el maricón hambriento de "besos brujos", el maricón drogado por el tacto imaginario de una mano volantín rozando el cielo turbio de su carne, el maricón infinitamente preso por la lepra coliflora de su jaula, el maricón trululú, atrapado en su telaraña melancólica de rizos y embelecos, el maricón rififí, entretejido, hilvanado en los pespuntes de su propia trama (Lemebel, 2002: 38).

Si comparamos a "la loca" de Tengo miedo torero con "la loca" de El lugar sin limites, ambos personajes siguen el mismo itinerario abyecto, que se vale de la ocasión, de la miseria e infortunio de otros para su satisfacción; la Manuela sirve de pasatiempo, objeto de burla y escarnio que encuentra

24 "El primer gran intento teórico de desexualizar el placer no fue la Historia de la sexualidad de Foucault, sino Tres ensayos de teoría sexual de Freud, (...). Es esta obra la que planteó por primera vez (...) la posibilidad de disolver toda noción de sexo en una reorganización de los placeres corporales" Bersani (1998: 117).

${ }^{25}$ En este sentido, comparte algunos rasgos con la temática de la abyección que Genet desarrolla en sus libros y que ha sido estudiada por Bersani (1998: 171-178) y también por Eribon (2004: 117-137).

${ }^{26}$ Eufemismo de recto: "última parte del intestino grueso, que empieza en el colon y termina en el ano”, ya que orto (del griego orthós) significa recto: véase Moliner, 1988. 
su placer en el castigo corporal, en la humillación y en el desprecio que le imponen los que detentan el poder; el texto descubre los lugares sin límites donde desborda la crueldad, la intolerancia, el juego perverso que la sexualidad hegemónica induce para poner límites a la transgresión. En la novela de Lemebel se muestra el "sexo malandra", el circunstancial, que proporciona la casualidad y que tiene precio; y también aquel sexo que profita de las necesidades de los menesterosos y que coloca al homosexual en el lugar infame, turbio y equívoco donde advierte que puede ejercer el mismo poder malévolo de las estructuras dominantes sobres seres eventualmente más débiles que él.

\section{CONCLUSIONES}

La distancia temporal que separa ambas novelas mide la diferencia entre los constructos sociales de "la loca". En la novela de José Donoso, la identidad de la Manuela se construye como un efecto performativo del nombre y del vestido, en conjunción con el instante preciso en que el baile borra el cuerpo envejecido, la boca desdentada o la magra figura. En efecto, en la Manuela confluye la ilusión de un cuerpo inexistente, el deseo que este espejismo suscita en los parroquianos del burdel y la ira que surge cuando la realidad impone su triste pátina de crueldad y desolación sobre un cuerpo arruinado por el alcohol, los años y la pobreza; se trata de una identidad precaria, inestable y frágil que se destruye cada vez que se impone la materialidad de un cuerpo que no puede mantener la ilusión de ser otro(a). Por el contrario, la identidad de la Loca del Frente, aunque ligada también al vestido y a la imagen ficticia que proyecta, impone su existencia más allá de los signos convencionales; se trata de una realidad que emerge para destruir el binarismo en el mundo: sabe que su historia de amor no es objeto de los relatos destinados a mantener la disciplina de los cuerpos pues el texto opta por un final que le resta importancia a la experiencia trascendental del amor: el mantel bordado por "la loca" es arrastrado por la marea del atardecer como las "avecitas locas/ que quieren volar...", todos signos de aglutinación de un sólo sentido, cual es la inminencia de la separación y la imposibilidad del final feliz. Pero a pesar del distanciamiento que el(la) protagonista toma frente a la tragedia del amor no correspondido, persiste la dignidad y el autorrespeto adquirido por la Loca del Frente en su complicidad con la subversión y su pasión por uno de los conspiradores. Punto de inflexión de las dos novelas: mientras la Manuela sucumbe a las prácticas coercitivas de la 
hegemonía terrateniente, heterosexual y blanca, la Loca del Frente cuestiona su asimilación a los modelos de dominación: el bordado y su imaginación, puestos al servicio de las esposas de los generales de la República, son una muestra de sumisión y de pertenencia a la marginalidad que debe conformarse con el lugar que el Poder le asigna.

En suma, el travestismo de la Manuela no cuestiona la norma sexual porque el vestido no es usado como una forma de resistencia en contra del Poder, sino como la licencia que este mismo autoriza para asegurar el control sobre la sociedad agrícola del lugar. La Manuela es lo anormal y lo monstruoso confinado al prostíbulo y destinado a servir de chivo expiatorio cada vez que la heterosexualidad se permite estos juegos equívocos que refuerzan en el sentido de Butler la originalidad y la norma de sus prácticas. En cambio, la Loca del Frente utiliza el vestido para su placer, para crear la ilusión de un cuerpo otro, pero que en el devenir del relato termina usándolo para conspirar en contra de la tiranía política, que subsume cualquier otra dominación, por lo que puede considerársele una forma de rechazo a los modelos sexuales impuesto por el binarismo heterosexual.

\section{REFERENCIAS}

Austin, John.L. 1982. Cómo hacer cosas con palabras. Barcelona: Paidós. Bersani, Leo. 1998. Homos. Buenos Aires: Manantial.

Bourdieu, Pierre. 2001. La dominación masculina. Barcelona: Anagrama.

Brunet, Marta. 1962. Amasijo. Santiago: Zig-Zag.

Butler, Judith. 2005. Cuerpos que importan: sobre los limites materiales y discursivos del "sexo". Buenos Aires: Editorial Paidós.

2006. Deshacer el género. Barcelona: Editorial Paidós.

Canovas, Rodrigo. 2000. "Una relectura de El lugar sin límites, de José Donoso, en Anales de Literatura Chilena 1, pp. 87-99.

Chemama, R. 1998: Diccionario del psicoanálisis. Buenos Aires: Amorrortu.

Chevalier, Jean y Gheerbrant, Alain.1982. Dictionnaire des symboles. París: Éd. Robert Laffont / Jupiter.

Deleuze, Gilles. 1990. "Sur la philosophie", en Pourparlers. París: Minuit, pp. 206.

Donoso, José. 1981 [1966]. El lugar sin limites. Barcelona: Bruguera.

Eribon, Didier. 2001. Reflexiones sobre la cuestión gay. Barcelona: Anagrama. . 2004. Una moral de lo minoritario. Barcelona: Anagrama. 
Foster, David William 1997. La diáspora homoerótica en América Latina. Arizona State University.

Foucault, Michel. 1990. La vida de los hombres infames. Madrid: Ediciones La Piqueta. .2001. Historia de la sexualidad. México: Siglo Veintiuno Editores.

Jeftanovic, Andrea. 2010. Entrevista a Pedro Lemebel: El cronista de los márgenes. (En línea). Disponible en www.planznow.com/archived_site/ texto3.html. Consulta: 03/12/2010.

Kosofsky Sedgwick, Eve.1998. Epistemología del armario. Barcelona: Ediciones de la Tempestad.

Lemebel, Pedro. 2002. Tengo miedo torero. Santiago: Seix Barral. 1994. Loco afán. Crónicas de sidario. Santiago: LOM.

López, Berta. 2005. "Tengo miedo torero, de Pedro Lemebel: ruptura y testimonio", en Estudios Filológicos 40, pp. 121-129.

Moliner, M. 1988. Diccionario de uso del español. Madrid: Gredos.

Sarrochi, Augusto C. 1992. El simbolismo en la obra de José Donoso. Santiago de Chile: La Noria. 